\title{
Delays to Large Construction Projects in Ghana: A Risk Overview
}

\author{
Joseph Ignatius Teye Buertey ${ }^{1}$, Augustine Kaku Miezah ${ }^{2}$ and Theophilus Adjei Kumi ${ }^{3}$ \\ 1. Faculty of Engineering \& Computing, Pentecost University College, Kaneshie \# KN 1739, Ghana \\ 2. Takoradi Thermal Power Station, Volta River Authority, Takoradi \# TD237, Ghana \\ 3. Department of Building Technology, Kwame Nkrumah University of Science and Technology, Kumasi \# UPO 000, Ghana
}

\begin{abstract}
Delay to large scale projects, which is as a result of actions or inactions of some project stakeholders, is becoming a global phenomena and Ghana is no exception. The objective of the research is to identify, rate and rank the most significant risk factors that causes delay on projects and examine the social impact of these delays to recommend modalities to help mitigate these risk factors. The study adopted quantitative methods with the distribution of 144 questionnaires to built environment professionals receiving a response rate of $75.7 \%$. The instrument listed 58 common factors under eight categories that contribute to the causes of delay for respondents to rate. Analysis of data non-parametric test revealed that client, contractor, material and finance category factors significantly resulted in the schedule delay of large infrastructural projects. The survey analysis revealed that micro-factors that result in delays to large construction projects are time constraint, cost overrun, payment problems, dispute and litigation. The research recommended the following modalities to minimize such delays: availability of resources, improved communication and coordination, proper scope definition and feasibilities, utilization of modern technology, appropriate application of technologically based systems and competent project management's structures.
\end{abstract}

Key words: Cost overruns, delayed payment, disputes, risk and social impact.

\section{Introduction}

The construction industry is challenged by serious schedule overruns. The above assertion was confirmed by Buertey et al. [1] who reveal that about $95 \%$ of projects executed in Ghana suffer from schedule delays. After a review of holds key indicators for the success of construction projects, Danso and Fugar [2] revealed that at least $25 \%$ of projects executed under the local government set up fails due to schedule overruns. To confirm the above assertion, Baiden-Amissah [3], at 5\% level of significance, using 95\% confident limit, revealed that all projects executed in the certain parts of Ghana fails to achieve the key project objective. According to Young et al. the most common tool for measuring the performance

Corresponding author: Joseph Ignatius Teye Buertey, M.Sc., lecturer, research fields: project risk management, procurement management and cost management. E-mail: jbuert@yahoo.co.uk. of various governments in developing countries such as Ghana has been economic growth and infrastructure development. The prudent management of the construction industry is a key performance indicator for measuring the performance of governments in developing countries due to the huge money which is normally allocated for in their annual budgets. Buertey et al. [1] reiterated that the economic reason for the failure of developmental project has detrimental effect on the schedule completion time.

In line with the above challenges, the main drivers behind this research are to identify, rate and rank specific causes of delay on projects and recommend modalities to ensure that delays on construction projects are minimized. Buertey et al. [4] revealed that the challenge of time overrun results in schedule delay, possible cost overruns as the project continues to delay, a delay in the use of the project downstream and social benefit. 
The prudent management of the construction industry is a key performance indicator for measuring the performance of governments in developing countries due to the huge money which is normally allocated for in their annual budgets. Buertey et al. [4] reiterated that the economic reason for the failure of developmental project has detrimental effect on the schedule completion time.

Kerzner [5] postulates that project success is "a continuous stream of successfully managed project”, when it achieves all the project goals and objectives while honoring the preconceived project constraint; Otherwise, it is a challenged or failed project. The definition of project success today embodies the completion of project: with a minimum or mutual agreed scope changes, without disturbing the main work flow of the organization and without changing the corporate culture. In our quest to complete projects within the original scope, without disturbing the work flow and maintaining the culture or standards of the organisation one is bound to face the challenge of schedule changes. Along the project execution trajectory, variations in scope of work are inevitable, with these changes in design, construction technology or specifications normally lead to schedule overruns. Tom [6] holds that many contracts are ambiguous when it comes to defining delay and who bears the financial burden of the added costs associated with added contract performance time. Although delays in project are becoming a global phenomenon, the causes of this phenomenon may differ from one country to another due to different cultures, political, economical and geographical factors among others.

Like any human undertaking, projects need to be performed and delivered under certain constraints. Traditionally, these constraints have been listed as "scope", "time” and "cost”. These are called Triple Constraint also referred to as the "project management triangle” where each side represents a constraint. One side of the triangle can not be changed without affecting the others. A further refinement of the constraints separates product “quality” or “performance” from scope, and turns quality into a fourth constraint [7].

The time constraint refers to the limited amount of time available to complete a project, in relation to unexecuted works and available resources. This constraint governs the basic requirement of project management that is, the project should be completed on or before the time scheduled. All projects are developed in order to adhere to some initial determined technical specification. The scope constraint refers to what must be done to produce the project's end result. Naturally, clients expect that the project being developed on their behalf will work as expected. Applying this criterion is often referred as conducting “quality” check [8]. These three constraints are often competing constraints. Their relations are as shown in Table 1.

\section{Conceptual Framework}

Project schedule delay is a situation when the contractor and or the client jointly or severally contribute to the non-completion of the project within the original or the stipulated or agreed contract period. Delays can result in disruption of work and loss of productivity, late completion of project, increased time, related costs and third party claims and abandonment or termination of contract. When projects are delayed, they are either accelerated which may result in poor performance or have their duration extended beyond the scheduled completion date, resulting in the delay in the use of the facility by stakeholders. "Many contracts are ambiguous when it comes to defining delay and who bears the financial burden of the added costs associated with added contract performance time" [6].

Table 1 Project constraints and implication [9].

\begin{tabular}{ll}
\hline Constraints & Implication/results \\
\hline Increased scope & Increased time and increased cost \\
Tight time & Increased costs and reduced scope \\
Tight budget & Increased time and reduced scope \\
\hline
\end{tabular}


The classification of delays are critically determined by the terms and conditions specified in the contract [10]. In the absence of a contractual definition, generally the construction industry recognizes three types of delay. Jamil [11] held that delays could be classified into three basic categories as follows:

(1) excusable delays with compensation;

(2) excusable delays without compensation;

(3) non-excusable delays.

Excusable delays as simply delays at no fault to the contractor; these are delays that are not attributable to the contractor's actions or inactions. These delays are caused by unforeseen events and the events are beyond the control of the contractor. Examples of excusable delays are design problems, owner-initiated changes, unusually severe weather, fire, natural disasters and other force majeure conditions. Excusable delays justify an extension of a contract's deadline, and mostly classified as compensation events [12].

In the event of excusable delays, time extension is owed to the contractor where time extension is required as a result of affected scheduled time and an owner cannot recover liquidated or actual damages that may have been sustained because of a delay [13]. Excusable delays are further classified into compensable and non-compensable delays.

According to the standard of contract, compensable delays are delays where the contractor is owed money to compensate for the loss due to the delay. Excusable delays with compensation are caused by the client's actions or inactions. Examples of excusable delays with compensation are as directed changes, changed conditions, failure to fulfill contractual responsibilities or conditions constituting constructive changes by the client. Non-compensable delays are delays where a time extension is owed but no compensation is owed to the contractor. In non-compensable delays neither the client nor the contractor is deemed responsible. Some examples of excusable without compensation delays are any "act of God” or unprovoked strikes [14].

Majid and McCaffer [14] describes non-excusable delays as delays due to the contractor or sub-contractor's fault. Examples of non-excusable delays are underestimates of productivity, equipment breakdowns, improper project planning and scheduling, poor site management and supervision, wrong construction methods, unreliable subcontractors or suppliers.

Concurrent delay typically becomes a much contested issue on those projects that experience more than one of these types of delays. The vast majority of projects that are finished late fall into this category. Concurrent delay is experienced on a project when two or more separate delay events occur during the same time period and each independently affects the completion date [12]. In analyzing concurrent delays, each delay is assessed separately and its impact on other activities and the project duration is calculated. The following are guidelines for classifying these kinds of concurrent delays:

- In the event of excusable and non-excusable delays occurring concurrently, a time extension is granted to the contractor;

- If excusable with compensation and excusable without compensation delays occur concurrently, the contractor is entitled to time extension, but not to damages;

- If two excusable with compensation delays occur concurrently, the contractor is entitled to both time extension and damages [14].

If these basic delay guidelines are not addressed in the contract documents, it is certain that discussions regarding concurrent combinations of these guidelines will be both heated and protracted.

In relation to the causes of delay, Abdalla and Hussien [15], identified the causes of construction delays construction delays are due to owner interference, inadequate contractor experience, financing and payments, labor productivity, slow decision making, improper planning, and 
subcontractor defaults.

Wong et al. [16] revealed that the principal contributors to project delay were improper site co-ordination and management of the electrical and mechanical installations, lack of timely decision making of the client, and defects identified during the fire services inspection by local authorities, site management and supervision, workload of the project staff, the procedures for equipment approval and working experience of the parties. Sweis et al. [17] studied delays in the construction industry in the residential projects and held that financial difficulties faced by the contractor and too many change orders by the owner are the leading causes of construction delay. Severe weather conditions and changes in government regulations and laws ranked among the least important causes.

Based on the forgoing, numerous risk factors affecting project schedule are identified these could be categorized as contractor, client, consultant, materials, financial, labor, equipment and external related.

\section{Research Methodology}

\subsection{Population}

This paper is based on a mix methodological approach of data collection: quantitative and qualitative procedures. With the application of the quantitative data collection, a survey questionnaire was designed and administered to stakeholders and professionals in the built environment working on developmental projects in Ghana to gather data to determine the risk impact of scope changes in the various work sections and its eventual effect on the contingency margins of the project. The sample size for this work was determined using the statistical relation by Kumar [18], Clarke and Cook [19]. In all, 144 questionnaires were distributed and 144 (75.7\%) were retrieved as depicted in Table 2. All questionnaires were administered personally to the respondent during which advantage was taken to interview some top and middle level management staff. Respondents were given three weeks to fill the questionnaires after which the questionnaires were personally collected for analysis.

\subsection{Questionnaire Design and Data Collection}

The survey instrument had two categories of questions: factors causing the delay to the construction projects and the impact of the risk factors. Fifty eight risk factors identified were grouped under eight categorized: client, contractor, consultant, financial, material, equipment, labor and external related delays. These were tabulated for respondent to rate on a 10 point scale as displayed in Tables 2-10.

\subsection{Data Analysis}

In each group, the factors were ranked based on frequency index, severity index and importance index. The importance index was derived from frequency index and severity index as generated from the three principal parties of construction, thus clients, consultants and contractors.

Basing on the fifty eight factors of leading causes of delays in large scale construction projects identified, the factors were categorized into eight major groups as.

In each group, the factors were ranked based on importance index. The average index ranked by the three respondents, thus clients, consultants and contractors were tabulated. The average importance

Table 2 Questionnaire distribution demography.

\begin{tabular}{lccl}
\hline Type of respondent & Total out & No. of responses & Proportion of total sample size (\%) \\
\hline Consultants & 48 & 40 & $83.3 \%$ \\
Client's firms & 48 & 34 & $70.3 \%$ \\
Contractors & 48 & 35 & $72.9 \%$ \\
\hline Total & 144 & 109 & $75.7 \%$ \\
\hline
\end{tabular}


Table 3 Result of major delay groups.

\begin{tabular}{|c|c|c|c|c|c|c|c|c|c|}
\hline \multirow{2}{*}{ Groups } & \multicolumn{2}{|c|}{ Client } & \multicolumn{2}{|c|}{ Consultant } & \multicolumn{2}{|c|}{ Contractor } & \multicolumn{2}{|c|}{ Overall } & \multirow{2}{*}{$\begin{array}{l}\text { Spearman rank } \\
\text { coefficient } r_{s}\end{array}$} \\
\hline & Index & Rank & Index & Rank & Index & Rank & Mean & Rank & \\
\hline Client & 0.456 & 4 & 0.589 & 2 & 0.523 & 2 & 0.523 & 1 & \multirow{8}{*}{$r_{s}=0.976$} \\
\hline Contractor & 0.447 & 5 & 0.594 & 1 & 0.524 & 1 & 0.522 & 2 & \\
\hline Material & 0.509 & 2 & 0.544 & 4 & 0.509 & 3 & 0.521 & 3 & \\
\hline Finance & 0.513 & 1 & 0.544 & 4 & 0.502 & 4 & 0.520 & 4 & \\
\hline Equipment & 0.462 & 3 & 0.557 & 3 & 0.502 & 4 & 0.507 & 5 & \\
\hline External & 0.442 & 7 & 0.523 & 6 & 0.481 & 6 & 0.482 & 6 & \\
\hline Consultant & 0.444 & 6 & 0.497 & 8 & 0.455 & 8 & 0.465 & 7 & \\
\hline Labor & 0.406 & 8 & 0.511 & 7 & 0.467 & 7 & 0.461 & 8 & \\
\hline
\end{tabular}

Table 4 Result of client related delays.

\begin{tabular}{|c|c|c|c|c|c|}
\hline \multirow{2}{*}{ Delay factors (client related delays) } & \multicolumn{2}{|c|}{ Consultant } & \multicolumn{2}{|c|}{ Contractor } & \multirow{2}{*}{ Spearman rank coefficient $\left(r_{s}\right)$} \\
\hline & Index & Rank & Index & Rank & \\
\hline Change orders during construction & 0.554 & 6 & 0.517 & 6 & \\
\hline Improper project feasibility study & 0.684 & 1 & 0.538 & 4 & \\
\hline Delay to furnish and delivery of site to the contractor & 0.567 & 4 & 0.526 & 5 & \\
\hline Lack of communication and coordination & 0.654 & 2 & 0.596 & 1 & $r_{s}=0.995$ \\
\hline Slow decision making process & 0.567 & 4 & 0.540 & 3 & \\
\hline Client interference & 0.582 & 3 & 0.542 & 2 & \\
\hline Lack of capable representative & 0.515 & 7 & 0.405 & 7 & \\
\hline
\end{tabular}

Table 5 Result of contractor related delays.

\begin{tabular}{|c|c|c|c|c|c|}
\hline \multirow{2}{*}{ Delay factors (contractor related delays) } & \multicolumn{2}{|c|}{ Consultant } & \multicolumn{2}{|c|}{ Contractor } & \multirow{2}{*}{-Spearman rank coefficient $r_{s}$} \\
\hline & Index & Rank & Index & Rank & \\
\hline Improper project planning and scheduling & 0.609 & 4 & 0.611 & 1 & \multirow{10}{*}{$r_{s}=0.539$} \\
\hline Poor site management and supervision & 0.597 & 5 & 0.501 & 8 & \\
\hline Inaccurate time estimate & 0.584 & 6 & 0.528 & 4 & \\
\hline Obsolete construction methods & 0.563 & 9 & 0.502 & 7 & \\
\hline Inaccurate cost estimate & 0.584 & 6 & 0.542 & 2 & \\
\hline Incompetent project team & 0.623 & 2 & 0.503 & 6 & \\
\hline Rework due to errors during construction & 0.624 & 3 & 0.528 & 4 & \\
\hline Obsolete technology & 0.571 & 7 & 0.490 & 10 & \\
\hline Unreliable subcontractor & 0.542 & 10 & 0.501 & 8 & \\
\hline Inadequate contractor experience & 0.640 & 1 & 0.529 & 3 & \\
\hline
\end{tabular}

Table 6 Result of consultant related delays.

\begin{tabular}{|c|c|c|c|c|c|}
\hline \multirow{2}{*}{ Delay factors (consultant related delays) } & \multicolumn{2}{|c|}{ Consultant } & \multicolumn{2}{|c|}{ Contractor } & \multirow{2}{*}{ - Spearman rank coefficient $r_{s}$} \\
\hline & Index & Rank & Index & Rank & \\
\hline Inadequate project management assistance & 0.370 & 7 & 0.441 & 7 & \\
\hline Inadequate consultant experience & 0.524 & 3 & 0.465 & 3 & \\
\hline Inaccurate site investigation & 0.609 & 1 & 0.542 & 1 & \\
\hline Slow response and poor inspection & 0.502 & 4 & 0.449 & 6 & $r_{s}=0.768$ \\
\hline Unclear and inadequate details in drawings & 0.428 & 6 & 0.453 & 5 & \\
\hline Poor design and delays in design & 0.542 & 2 & 0.360 & 4 & \\
\hline Delay in approving changes in the scope of work & 0.502 & 4 & 0.476 & 2 & \\
\hline
\end{tabular}


Table 7 Result of finance related delays (ranking of consultant and contractor's response).

\begin{tabular}{|c|c|c|c|c|c|}
\hline \multirow{2}{*}{ Delay factors (finance related delays) } & \multicolumn{2}{|c|}{ Consultant } & \multicolumn{2}{|c|}{ Contractor } & \multirow{2}{*}{-Spearman rank coefficient $r_{s}$} \\
\hline & Index & Rank & Index & Rank & \\
\hline Inadequate fund allocation & 0.453 & 6 & 0.472 & 6 & \\
\hline Contractor's financial difficulties & 0.415 & 7 & 0.515 & 3 & \\
\hline Client’s financial difficulties & 0.626 & 1 & 0.503 & 4 & \\
\hline Delay in payment of suppliers and subcontractors & 0.611 & 3 & 0.476 & 5 & $r_{s}=-0.321$ \\
\hline Poor cash flow management & 0.580 & 4 & 0.528 & 2 & \\
\hline High interest rate & 0.622 & 2 & 0.464 & 7 & \\
\hline Bureaucracy in procurement system & 0.501 & 5 & 0.555 & 1 & \\
\hline
\end{tabular}

Table 8 Result of Finance related delays (ranking of client and contractor's response).

\begin{tabular}{|c|c|c|c|c|c|}
\hline \multirow{2}{*}{ Delay factors (finance related delays) } & \multicolumn{2}{|c|}{ Client } & \multicolumn{2}{|c|}{ Contractor } & \multirow{2}{*}{ Spearman rank coefficient $r_{s}$} \\
\hline & Index & Rank & Index & Rank & \\
\hline Inadequate fund allocation & 0.468 & 7 & 0.472 & 6 & \\
\hline Contractor's financial difficulties & 0.556 & 1 & 0.515 & 3 & \\
\hline Client's financial difficulties & 0.479 & 6 & 0.503 & 4 & \\
\hline Delay in payment of suppliers and subcontractors & 0.510 & 4 & 0.476 & 5 & $r_{s}=0.357$ \\
\hline Poor cash flow management & 0.489 & 5 & 0.528 & 2 & \\
\hline High interest rate & 0.534 & 3 & 0.464 & 7 & \\
\hline Bureaucracy in procurement system & 0.554 & 2 & 0.555 & 1 & \\
\hline
\end{tabular}

Table 9 Result of material related delays (ranking of consultant and contractors response).

\begin{tabular}{|c|c|c|c|c|c|}
\hline \multirow{2}{*}{ Delay factors (material related delays) } & \multicolumn{2}{|c|}{ Consultant } & \multicolumn{2}{|c|}{ Contractor } & \multirow{2}{*}{-Spearman rank coefficient $r_{s}$} \\
\hline & Index & Rank & Index & Rank & \\
\hline Shortage of materials in market & 0.529 & 7 & 0.555 & 2 & \multirow{8}{*}{$r_{s}=-0.595$} \\
\hline Changes in types and specifications of materials & 0.490 & 8 & 0.569 & 1 & \\
\hline Escalation of material prices & 0.567 & 4 & 0.554 & 3 & \\
\hline Unreliable suppliers & 0.608 & 1 & 0.515 & 4 & \\
\hline Late delivery of materials & 0.567 & 3 & 0.476 & 6 & \\
\hline Unrealistic procurement strategy & 0.584 & 2 & 0.438 & 8 & \\
\hline Poor quality of materials & 0.542 & 5 & 0.449 & 7 & \\
\hline Underestimation of materials & 0.542 & 5 & 0.515 & 4 & \\
\hline
\end{tabular}

Table 10 Result of material related delays (ranking of client and contractors response).

\begin{tabular}{|c|c|c|c|c|c|}
\hline \multirow{2}{*}{ Delay factors (material related delays) } & \multicolumn{2}{|c|}{ Client } & \multicolumn{2}{|c|}{ Contractor } & \multirow{2}{*}{-Spearman rank coefficient $r_{s}$} \\
\hline & Index & Rank & Index & Rank & \\
\hline Shortage of materials in market & 0.543 & 2 & 0.555 & 2 & \multirow{8}{*}{$r_{s}=0.417$} \\
\hline Changes in types and specifications of materials & 0.500 & 5 & 0.569 & 1 & \\
\hline Escalation of material prices & 0.512 & 4 & 0.554 & 3 & \\
\hline Unreliable suppliers & 0.469 & 7 & 0.515 & 4 & \\
\hline Late delivery of materials & 0.522 & 3 & 0.476 & 6 & \\
\hline Unrealistic procurement strategy & 0.489 & 6 & 0.438 & 8 & \\
\hline Poor quality of materials & 0.423 & 8 & 0.449 & 7 & \\
\hline Underestimation of materials & 0.613 & 1 & 0.515 & 4 & \\
\hline
\end{tabular}

indices of the three respondents were calculated for the final ranking of the categorized groups. These average importance indices were ranked from the viewpoint of consultants and contractors while ignoring the ranking of the third respondent. Eq. (1) was used for this calculation and the Spearman's rank correlation coefficient $r_{s}$ as shown in Tables 3-13 [20]. 
Table 11 Result of equipment related delays.

\begin{tabular}{|c|c|c|c|c|c|}
\hline \multirow{2}{*}{ Delay factors (equipment related delays) } & \multicolumn{2}{|c|}{ Consultant } & \multicolumn{2}{|c|}{ Contractor } & \multirow{2}{*}{-Spearman rank coefficient $r_{s}$} \\
\hline & Index & Rank & Index & Rank & \\
\hline Frequent breakdown of equipment & 0.515 & 5 & 0.477 & 5 & \multirow{6}{*}{$r_{s}=0.771$} \\
\hline Inadequate number of equipment & 0.515 & 5 & 0.490 & 4 & \\
\hline Lack of high-technology equipment & 0.684 & 1 & 0.524 & 2 & \\
\hline Lack of equipment parts for replacement & 0.542 & 3 & 0.477 & 5 & \\
\hline Equipment mobilization problem & 0.555 & 2 & 0.528 & 1 & \\
\hline Equipment allocation problem & 0.529 & 4 & 0.515 & 3 & \\
\hline
\end{tabular}

Table 12 Result of labour related delays.

\begin{tabular}{|c|c|c|c|c|c|}
\hline \multirow{2}{*}{ Delay factors (labour related delays) } & \multicolumn{2}{|c|}{ Consultant } & \multicolumn{2}{|c|}{ Contractor } & \multirow{2}{*}{-Spearman Rank Coefficient $r_{s}$} \\
\hline & Index & Rank & Index & Rank & \\
\hline Low motivation and morale & 0.582 & 2 & 0.462 & 5 & \\
\hline Slow mobilization of labour & 0.477 & 6 & 0.453 & 6 & \\
\hline Low labour productivity & 0.515 & 4 & 0.490 & 3 & \\
\hline Scarcity of skilled labour & 0.425 & 3 & 0.371 & 7 & $r_{s}=0.214$ \\
\hline Absenteeism & 0.515 & 4 & 0.515 & 1 & \\
\hline Misunderstanding among workforce & 0.453 & 7 & 0.465 & 4 & \\
\hline Frequent strike action & 0.609 & 1 & 0.515 & 1 & \\
\hline
\end{tabular}

Table 13 Result of external related delays.

\begin{tabular}{|c|c|c|c|c|c|}
\hline \multirow{2}{*}{ Delay factors (external related delays) } & \multicolumn{2}{|c|}{ Consultant } & \multicolumn{2}{|c|}{ Contractor } & \multirow{2}{*}{-Spearman rank coefficient $r_{s}$} \\
\hline & Index & Rank & Index & Rank & \\
\hline Unforeseen ground condition & 0.503 & 4 & 0.451 & 6 & \multirow{6}{*}{$r_{s}=0.571$} \\
\hline Delay in obtaining permits from authorities & 0.555 & 2 & 0.542 & 1 & \\
\hline Inflation/prices fluctuation & 0.584 & 1 & 0.486 & 3 & \\
\hline Weather condition & 0.464 & 6 & 0.453 & 4 & \\
\hline Conflict or war in community & 0.542 & 3 & 0.489 & 2 & \\
\hline Unavailability of utilities at site & 0.489 & 5 & 0.453 & 4 & \\
\hline
\end{tabular}

The Spearman's rank correlation coefficient was calculated as a relationship measure among different parties or factors and the strength and direction of the relationship. In this research analysis the Spearman's rank correlation coefficient is used to show the degree of agreement between the different respondents. The Spearman's rank correlation is a non-parametric test. Non-parametric tests are also referred to as distribution-free tests. These tests have the obvious advantage of not requiring the assumption of normality or the assumption of homogeneity of variance. They compare medians rather than means and, as a result, if the data have one or two outliers, their influence is negated. The correlation coefficient varies between +1 and -1 , where +1 implies a perfect positive relationship (agreement), while -1 results from a perfect negative relationship (disagreement). It might be said then that sample estimates of correlation close to unity in magnitude imply good correlation, while values near zero indicate little or no correlation.

The Spearman's rank correlation coefficient $\left(r_{s}\right)$ is used to measure and compare the association between the rankings of two respondents for a single cause of delay, while ignoring the ranking of the third respondent. Spearman's rank coefficient $\left(r_{s}\right)$ is calculated by the following formula:

$$
r_{s}=1-\frac{6 \sum_{d} 2}{N\left(N^{2}-1\right)}
$$

where:

$r_{s}$ is Spearman's rank correlation coefficient; 
$d$ is the difference in ranking between contractor and consultant or contractor and client, or consultant and client, i.e., between any two respondents;

$N$ is the number of variables, respectively.

The importance index were further used to calculate the Spearman's rank correlation coefficient and the null hypothesis to analyze and establish the level of agreement of correlation in the ranking between paired groups of the respondents

\section{Findings and Discussions}

With respect to client related delays, the sample estimates a correlation close to unity in magnitude ( $r_{s}$ $=0.976)$. This result implies a good correlation between respondent of consultant and contractor. As a result of the good correlation of the client related delays it was also observed that the high ranked factors in this group such as lack of communication and coordination, improper project feasibility study were among the top five ranked factors of the study. The study shows the data of factors of contractor related delays. This is the group with the highest number of factors. This implies there are many associated factors relating to the contractor which may lead to delays in large scale construction projects. It therefore calls for attention, coordination and communication between the client and the contractor as has been identified from the importance index ranking earlier as the number one factor in this study. A Spearman's rank correlation coefficient $r_{s}=0.539$ shows an agreement between the respondents.

For consultant related delays, this group of factors saw the respondents rating the cause of inaccurate site investigation being rated the highest in each case. This is a clear manifestation that if a site is not well investigated there is a risk of underground and construction problems which can to extent lead to abandonment of construction projects. The low ranking by the client indicates technical knowhow of site investigation, with a positive correlation of 0.768 Spearman's rank correlation coefficient $r_{s}$.
In relation to finance related delays, there was a $r_{s}$ of -0.321 , which indicates a disagreement between the respondents. However, There was a positive correlation between client and contractor, the $r_{s}$ was 0.357. These differences in agreement between these pair of parties explain how the three respondents are associated with finance when it comes to project execution. In project management, the major contract which involves the greater percentage of finance is between the client and the contractor. As such the two parties have a strong relationship in finance than any other stakeholder hence the reflection in the ranking of factors of financial related delays.

With respect to material related delays, a similar scenario just as in financial related delay was demonstrated in the correlation among the respondents. There was a disagreement between consultant and contractor from the calculate Spearman's rank correlation coefficient $r_{s}$ (-0.595). The correlation between client and contractor was positive with Spearman's rank correlation coefficient $r_{s}=0.417$. The agreement and disagreement among the respondents show the working relationships in project management.

For equipment related delays, a Spearman's rank correlation coefficient $r_{s}$ of 0.7 indicates strong agreement in the correlation among the respondents for these factors. The ranking high of lack of high-technology equipment and equipment mobilization problem in this group suggests an investment to be made by contractors in Ghana.

For labor related delays, the experiences of frequent strike action was rated high whilst slow mobilization of labour was rated the least out of the seven factors. Strike actions may be caused by lack of communication and coordination as was earlier indicated. The reason could be a misunderstanding of the principle of vertical and horizontal communication in project management.

On the part of external related factors, it was observed that delay in obtaining permits from 
authorities and inflation/prices fluctuation are the factors which highly influences the delay of projects externally. These are caused by unnecessary bottlenecks created in obtaining permits for lack of knowledge in the time constraint in project management. On the other hand, inflation/price fluctuation is a problem associated with projects in developing countries which is some of the consequences of delays in project execution.

According to Table 2, the respondent, i.e., clients, consultants and contractors ranked the major delay groups in terms of importance as client related, contractor related, material related, finance related, external related, equipment related, consultant related and labor related groups, respectively. It was observed that the first four groups were rated closely in terms of magnitude of importance to delays in projects.

Beginning from client related groups, it was observed that out of the seven factors of delays in the group, four were listed in the top eighteen factors of the study. These factors are lack of communication and coordination, improper feasibility studies, client interference and slow decision making. It could be seen from the table that consultants rated improper feasibility higher than the other respondents. This could mean that there is a lack of communication and coordination as rated high by all respondents to the detail of scope of work for the consultant to perform his/her duty in the feasibility studies.

The contractor related group was rated second by the respondents. This group has ten related factors with four in the top eighteen factors. A significant observation in this group is that whilst contractors view and rank improper planning and scheduling as a high cause of delay, the other respondents ranked it low. The reason being that as discussed earlier the contractor requires a sufficient feasibility studies communicated well for him/her to have effective planning and scheduling. The conditions in third, fourth and fifth ranked groups are similar to the first two groups.
The labor related group was rated least. This group has none of the factors that cause delay ranked in the top eighteen factors. From the importance index rating in Table 4, it was observed that all respondents rated the factors of labor related delays. The above findings reveals how skilful and available Ghanaians professionals are in relation to industry practice.

Considering the above ratings and rankings, the effect of time constraint was ranked high followed by cost overrun and dispute at the same level. It is obvious from the constraint of project that delays in any phase of project will lead to time overrun according to the work schedule. The cause of time overrun is associated with cost in attempt to meet schedule. In some cases, the project team does work for extra hours and in some cases additional workers are hired. There are usually disputes when attempt is made to verify the cause of delay between client and contractor if the delay is compensable or non compensable delay. Therefore, the result is a true reflection of practice in project execution in Ghana.

The research confirms the finding by Al-Momani [21] which revealed in an earlier research conducted in Jordan which concluded that the main drivers of delays in construction projects relate to designers, user changes, weather, site conditions, late deliveries, economic conditions and increase in quantities.

In the Ghanaian front, Frimpong et al. [22] after studying the delays and cost overrun in groundwater construction projects in Ghana, revealed that the main causes of delay and cost overruns in construction of groundwater projects included: monthly payment difficulties from agencies, poor contractor management, material procurement, poor technical performances and escalation of material prices. The research concluded that effective project planning, controlling and monitoring should be established to enhance project performance in order to minimize or avoid delay and cost problems in groundwater construction projects.

Nguyen et al. [23] identified availability of 
resources, multidisciplinary/competent project team, competent project manager, accurate initial cost estimates and accurate initial time estimates as the main causes of schedule delay Wiguna and Scot [24] during their study of risks factors affecting construction delay and cost overruns in building projects revealed high inflation/increased material price, design change by owner, defective design, weather conditions, delayed payments on contract, and defective construction work who were the main drivers.

\section{Conclusions}

The research revealed that lack of project coordination, communication and poor scope definition are the major causes of these delays were the key attribute to the client related delays. In the same vein, poor site investigations and delay in supply of design information and change orders were ranked as the highest cause consultant delays.

In conclusion, it has been discovered that the client, contractor, material and finance were the major delay groups when it comes to delivery of major infrastructural projects. In general, the major factors that cause delays are time constraints, financial issues/changes in micro economic indicators, delayed payment problems, availability of resources, poor project management structures and lack of technologically based systems.

In order to significantly prevent and control delays in the future refining construction projects, it would be appropriate to underscore proactive guidelines for consideration. The result from the real situations showed that delays could be prevented and controlled by carrying out several important strategies during the implementation of the project. Making good use of planning and control for every project must take into account scope definition and scope control. Though the management of escalation in material prices is practically impossible, the contractor's cost management practices of advance ordering goods, defining the work breakdown structure and finance controlling management is imperative.

The above notwithstanding, to manage project configuration effectively, the contractor must endeavor to establish an effective communication system between all stake holders and partners of the building standard system for every process, surveying, collecting and deal with all of the information about weather and geological conditions of the site and other problem relating the site to make good decisions for constructions of the project.

With respect to the client, large scale projects require a well planned cash flow and proactive cash outlay for the project. As the main stakeholder and financier for the delivery of key infrastructural projects, the government must ensure the availability of adequate funds before commencing projects in order to ensure prompt payment to contractors at various phases of the project. Again, project delivery would be much enhanced if the selection of contractors for the procurement of infrastructural projects are politicized but based on competency, capability and financial muscle of the contractors and their power to deliver. The contractor must have adequate experience, technical capability, financial capability, and adequate manpower to execute the project in time. To enhance a smooth project execution, it is noteworthy for client to appoint professional and competent project managers to manage large scale projects and decision making process must be reduced and quick decision made to solve problems that arise during project execution.

On the part of the consultant's, the success of every project is hinged on the monitoring and control during the executing phase of the project to ensure that all key deliverables are met according to the project scope statement and quality standard. The consultants must be at all times and provide quick response to change orders raised by clients and contractors and the necessary details to prevent bottlenecks along the project execution phase. The contractor must also 
endeavour to provide competent and disciplinary workmen must be employed at site to reduce rework as this time and cost overrun to projects. Contractors must use high technology equipment to facilitate speedy completion of work. Contractors must provide detailed wok schedule, and followed closely to reduce delay in projects.

\section{References}

[1] J. Buertey, P. Amoa, T.A. Kumi, Construction cash flow prediction model: A case study of the district assembly common funded projects, in: Proceedings of the WABER (West Africa Built Environment Research) Conference, UK, 2010.

[2] A.K. Danso, F.D.K. Fugar, Capacity-building in construction administration: Key to effective utlisation of the district assembly common fund for infrastructural development, Journal of the Ghanaian Surveyor 2 (1) (2009) 1-5.

[3] P.D. Baiden-Ammissah, Enhancing the delivery performance of district assembly projects, M.Sc. Thesis, Department of Building Technology, Kwame Nkrumah University of Science and Technology, Kumasi, 2000.

[4] J.T.I. Buertey, E. Abeere-Inga, T.A. Kumi, Project cost contingency estimation in Ghana: An integrated approach science, Journal of Civil Engineering and Architecture 2012 (2012) 1-9.

[5] H. Kerzner, Project Management: A System Approach to Planning, Scheduling, and Controlling, 10th ed., John Willey \& Sons, Inc., Hoboken, New Jersey, 2009.

[6] P. Tom, The Cornerstone of Confidence, Nov. 2003, http//www.pinnacleone.com (accessed Aug. 10, 2011).

[7] Guide to the Project Management Body of Knowledge (PMBOK Guide), 4th ed., PMI (Project Management Institute), 2008.

[8] J.K. Pinto, Project Management, Achieving Competitive Advantage, Pearson Education Inc., New Jersey, 2007.

[9] S. Robertson, Project Classification, 2008, beepdf.com/doc/163938/project_classification.html (accessed Nov. 25, 2011).

[10] T.I. Olajide, O.O. Timo, A. Onaopepo, V.E. Idowu, Analysis of non excusable delay factors influencing contractors' performance in Lagos State, Nigeria, Journal of Construction in Developing Countries 18 (1) (2013)
53-72.

[11] S. Jamil, Construction Delay Analysis Methods, 2011, http://www.forensisgroup.com (accessed Nov. 11, 2011).

[12] P.E. Baram, E. George, Concurrent delays: What are they and how to deal with them?, in: AACE International Transactions, Morgantown, 2000.

[13] M.S. Phillips, When Are You Liable for Delay Damages?, 2004, http//www.professionalroofing.net (accessed July 22, 2011).

[14] A. Majid, R. McCaffer, Factors of non-excusable delays that influence contractors' performance, Journal of Management in Engineering 14 (3) (1998) 42-49.

[15] O. Abdalla, T.B. Hussien, Causes of construction delay: Traditional contracts, International Journal of Project Management 20 (1) (2002) 67-73.

[16] L.Y. Wong, N.K. Fong, L.T. Wong, Fire services installation related contributors of construction delay, Journal of Building and Environment 41 (2006) 211-222.

[17] G. Sweis, A.A. Hammad, A. Shboul, R. Sweis, Delays in construction projects: The case of Jordan, International Journal of Project Management 12 (6) (2008) 665-674.

[18] R. Kumar, Research Methodology: A Step by Step Guide For Beginners, SAGE Publications, London, 1999, pp. 48-55.

[19] G.M. Clark, D. Cook, A Basic Course in Statistics, 4th ed., Arnold, New York, 1998, pp. 18-45.

[20] C. Spearman, The proof and measurement of association between two things, Amer. J. Psychol. 15 (1904) 72-101.

[21] A. Al-Momani, Construction delay: Quantitative analysis, International Journal of Project Management 18 (2000) 51-59.

[22] Y. Frimpong, J. Oluwoye, L. Crawford, Causes of delay and cost overruns in construction of groundwater projects in developing countries, Ghana as a case study, International Journal of Project Management 21 (5) (2003) 321-326.

[23] L.D. Nguyen, S.O. Ogunlana, D.T.X. Lan, A study on project success factors in large construction projects in Vietnam, Journal of Engineering, Construction and Management 11 (6) (2004) 404-413.

[24] I.P.A. Wiguna, S. Scott, Analyzing the Risks Affecting Construction Delay and Cost Overruns in Indonesia Building Projects, Innovation in Architecture, Engineering and Construction, Rotterdam, 2005, pp. 841-849. 